\title{
Syntheses, structures and spectroscopy of polychlorinated dihydrocamphenes. An experimental and theoretical study
}

\author{
Jari J. Koivisto, ${ }^{* a}$ Erkki T. Kolehmainen, ${ }^{a}$ Vladimir A. Nikiforov, ${ }^{\text {b }}$ Maija J. Nissinen, ${ }^{a}$ Kari \\ A. Tuppurainen, ${ }^{c}$ Mikael Peräkylä, ${ }^{c}$ Sergei A. Miltsov, ${ }^{b}$ and Vladimir S. Karavan ${ }^{\text {b }}$ \\ ${ }^{a}$ Department of Chemistry, University of Jyväskylä, P.O. Box 35, FIN-40351 Jyväskylä, Finland \\ ${ }^{b}$ Institute of Chemistry, Laboratory of Physical Organic Chemistry, University of St.Petersburg, \\ Universitetskii pr. 2, 198904 St. Petersburg, Russia \\ ${ }^{c}$ Department of Chemistry, University of Kuopio, Snellmania, Savilahdentie 9 E, 70210 Kuopio, Finland \\ E-mail: M.Sc. Jari Koivisto: jarkoiv@cc.jyu.fi,Prof. Erkki Kolehmainen: ekolehma@cc.jyu.fi, Dr.Vladimir \\ Nikiforov: vn2076@vn2076.spb.edu,Lic.Phil.Maija Nissinen: majoni@cc.jyu.fi,Dr.Kari Tuppurainen: \\ Kari.Tuppurainen@uku.fi,Dr.Mikael Peräkylä: Mikael.Perakyla@uku.fi,Dr.Sergei Miltsov: \\ dm@sm2159.spb.edu, and Dr.Vladimir Karavan:vn2076@vn2076.spb.edu \\ *The author to whom the correspondence should be addressed: M.Sc. Jari Koivisto, Department of \\ Chemistry, University of Jyväskylä, P.O. Box 35, FIN-40351 Jyväskylä, Finland \\ E-mail:jarkoiv@cc.jyu.fi
}

(received 30 Sep 00; accepted 01 Jan 99; published on the web 20 May 02)

\begin{abstract}
Nine novel polychlorinated dihydrocamphenes (1-9) have been isolated from reaction mixtures obtained by the chlorination of lower chlorinated monoterpenes. These compounds are potential congeners of insecticide toxaphene. The ${ }^{1} \mathrm{H}$ and ${ }^{13} \mathrm{C}$ NMR spectra of 1-9 have been assigned by means of ${ }^{1} \mathrm{H},{ }^{1} \mathrm{H}$ DQF COSY (double-quantum filtered correlation spectroscopy), ${ }^{1} \mathrm{H},{ }^{1} \mathrm{H}$ ROESY (rotating frame nuclear Overhauser effect spectroscopy), $\mathrm{PFG}^{1} \mathrm{H},{ }^{13} \mathrm{C} \mathrm{HMQC}$ (pulsed field gradient heteronuclear multiple quantum coherence), ${ }^{1} \mathrm{H},{ }^{13} \mathrm{C}$ HMBC (heteronuclear multiple bond correlation) experiments, and computer aided ${ }^{1} \mathrm{H}$ NMR spectral analysis. In the case of $\mathbf{2}$, the structure has been determined by X-ray methods. Full geometry optimizations have been performed at the $a b$ initio $\mathrm{HF} / 6-31 \mathrm{G}^{*}$ level for a comparison with the conformational and structural properties obtained from the NMR- and X-ray experiments. The optimized geometries are in excellent agreement with the experimental structures. In addition, rotation barriers of compounds 7 and 9 have been characterized with the semiempirical AM1 method. The gauge-including atomic orbital (GIAO) method have been employed to calculate ${ }^{13} \mathrm{C}$ chemical shifts of 1-9 using density functional theory (DFT) at the B3LYP/6-311G* level and the $\mathrm{HF} / 6-31 \mathrm{G}^{*}$ optimized structures as geometry input. A comparison of the calculated and experimental data yielded a regression equation, which with added indicator variable (the number of chlorine atoms attached to each carbon) is capable of the accurate prediction of carbon chemical shifts for these compounds.
\end{abstract}

Keywords: 1D/2D NMR, ab initio, AM1, conformation, DFT, GIAO, MO calculations, polychlorinated dihydrocamphenes, stereochemistry, toxaphene, X-ray structure. 


\section{Introduction}

Toxaphene is an insecticidal mixture, which is produced by the controlled chlorination of camphene (2,2-dimethyl-3-methylene-bicyclo[2.2.1] heptane) under UV light. ${ }^{1}$ The initial ionic step of the chlorination leads via Wagner-Meerwein rearrangement pathway to bornane $(1,7,7-$ trimethyl-bicyclo[2.2.1]heptane) skeleton. The main intermediate products, 2-exo,10dichlorobornane (2-exo-chloro-1-chloromethyl-7,7-dimethylbicyclo[2.2.1]heptane) and 2exo,10,10-trichlorobornane (2-exo-chloro-1-dichloromethyl-7,7-dimethyl-bicyclo[2.2.1]heptane), are accompanied by other low chlorination hydrocarbons. ${ }^{2,3}$ Further radical chlorination leads to a complex mixture of highly chlorinated $\mathrm{C}_{10}$-terpenes.

For many years it was believed that toxaphene mixture primarily consists of chlorinated bornanes next to small amounts of chlorinated bornenes and even smaller amounts of chlorinated bornadienes. 4 The existence of polychlorinated bornenes and bornadienes had been postulated due to the GC/NCI-MS detection of substances with fragment masses being 2 or 4 amu below the [M-Cl]- ions of bornanes. Actually, these mass spectra must probably be attributed to camphenes, because new insights in synthetic pathways of technical toxaphene indicate the formation of camphenes and dihydrocamphenes. ${ }^{5}$

Previously, Landrum et al.6, ${ }^{7}$ reported the identification of a heptachlorodihydrocamphene in technical toxaphene and Hainzl et al. ${ }^{8}$ reported the isolation of five polychlorocamphenes from a toxaphene standard. In addition, Tribulovich et al. ${ }^{9}$ showed that cis- and trans-5-exo,10dichlorocamphenes (5-exochloro-3-chloromethylene-2,2-dimethyl-bicyclo[2.2.1]heptane) are possible precursors of polychlodihydrocamphenes in technical toxaphene.

It is known that the various toxaphene components are differently transformed in the environment; while some congeners are highly persistent, others are easily metabolized and not detectable in environmental samples. ${ }^{10}$ This leads to a simpler toxaphene residue pattern compared to the technical mixture. The composition in biota also varies depending on the trophic level and the ability of a species to metabolize selected toxaphene components. ${ }^{11}$ This implies that the orientation of the chlorine atoms may influence the chemical stability of toxaphene congeners. ${ }^{12}$ In addition, individual toxaphene congeners may exhibit different toxicity. ${ }^{13}$ Accordingly, the position and the number of the chlorine atoms on the molecule determines the magnitude and nature of biological effect. ${ }^{14}$ Consequently, an exact assignment of the stereochemistry of the chlorine atoms on the primary carbons is necessary for correct prediction of chemical reactivity and for correct assessment of degradation or accumulation in environment.

In this study, we report the syntheses, isolation and characterization of nine novel polychlorinated dihydrocamphenes 1-9. An exact description of position of the chlorine atoms on the primary carbons has been achieved by extensive one- and two-dimensional ${ }^{1} \mathrm{H}$ and ${ }^{13} \mathrm{C}$ NMR spectroscopy. In the case of 2, the structure has been determined by X-ray methods. The experimental results are compared with those obtained from $a b$ initio optimizations performed at the HF/6-31G* level. In addition, rotation barriers of compounds 7 and 9 have been characterized with the semiempirical AM1 method. ${ }^{15}$ 
${ }^{13} \mathrm{C}$ NMR chemical shifts can depend strongly on the conformation of a molecule. Accurate prediction of ${ }^{13} \mathrm{C}$ chemical shifts have become a tool that can complement ${ }^{1} \mathrm{H},{ }^{1} \mathrm{H}$ coupling constants, ${ }^{1} \mathrm{H},{ }^{1} \mathrm{H}$ NOE experiments, and empirical chemical shift correlations for elucidation of conformations and configurations of organic molecules. Bühl et al. ${ }^{16}$ have suggested that the combination of high-level $a b$ initio optimized geometries, theoretically computed NMR chemical shifts, and experimental NMR data provides a tool that can be routinely applied for structural determinations as well as the characterization of new compounds.

In this paper the gauge-including atomic orbital (GIAO) ${ }^{17}$ method have been employed to calculate ${ }^{13} \mathrm{C}$ chemical shifts of the polychlorinated dihydrocamphenes 1-9 using density functional theory (DFT) at the B3LYP/6-311G* level and the HF/6-31G* optimized structures as geometry input. From the data, a linear correlation between experimental and theoretical shifts has been derived. Furthermore, the predictive ability of the model has been improved by adding an indicator variable $\mathrm{N}_{\mathrm{Cl}}$ (the number of chlorine atoms attached to each carbon) to the regression equation.

\section{Results and Discussion}

\section{Formation of polychlorinated dihydrocamphenes}

In a first step of the toxaphene synthesis, a chloronium ion is added to the primary olefinic carbon of camphene. The positive charge in the six-membered ring is not localized on C3 but partially distributed on C4 and C5. According to the Markovnikov's rule the resulting stabilization of the positive charge in the non-classic carbocation results in no charge on C10. The non-classic carbocation primarily rearranges via a Wagner-Meerwein pathway to bornane by a nucleophilic attack of chlorine at $\mathrm{C} 4$ resulting in 2-exo,10-dichlorobornane. ${ }^{5}$

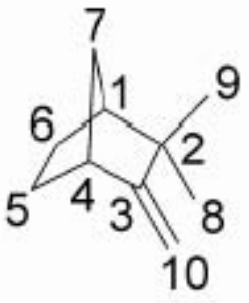

Camphene

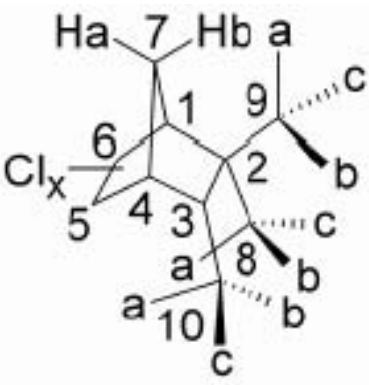

Polychlorinated dihydrocamphene

The formation of polychlorinated dihydrocamphenes is not as easy to understand as it would seem. Landrum et al. ${ }^{7}$ postulated addition of $\mathrm{HCl}$ to the double bond of camphene. According to Krock et al. ${ }^{5}$ this is very unlikely since an ionic attack at the double bond is more favourable due to the stabilization effect of the Wagner-Meerwein rearrangement resulting in the formation of bornane. Chlorination together with a retention of the camphene backbone occurs only if the 
Wagner-Meerwein rearrangement is hindered. ${ }^{5}$ Stabilization of the non-classic carbocation become difficult in the case of a chlorine substituent at $\mathrm{C} 5$. Krock et al. ${ }^{5}$ postulated that a chlorine substitution on C5 allows a stabilization of the positive charge due to delocalization between $\mathrm{C} 3, \mathrm{C} 4$, and $\mathrm{C} 7$. In comparison to the bornyl cation this carbocation is energetically less favoured due to the higher ring strain in the neighbouring fourmembered ring $(\mathrm{C} 1, \mathrm{C} 2, \mathrm{C} 3$, and C7). Krock et al. ${ }^{5}$ suggested that stabilization by addition of chlorine on $\mathrm{C} 4$ would lead to chlorinated pinane which is less favourable than the formation of dihydrocamphene generated by addition of chlorine at $\mathrm{C} 3$.

Therefore, Krock et al. ${ }^{5}$ proposed that all dihydrocamphenes should have chlorine atoms on C3, C5, and C10. This is indeed the case for all dihydrocamphenes described in this article and reported previously. $6,7,9$

\section{Crystal structure of 3-exo,5-exo,6-exo,9,10,10-hexachlorodihydrocamphene (2).}

The crystal structure of the hexachlorodihydrocxamphene 2 has been determined by single crystal X-ray diffraction measurement. The crystals of $3 \cdot \mathrm{C}_{10} \mathrm{H}_{12} \mathrm{Cl}_{6}$ possesses triclinic cell symmetry P1 (No. 2) with the lattice constants $\mathrm{a}=7.1965(2) \AA, \mathrm{b}=13.8275(5) \AA$, and $\mathrm{c}=$ 20.7769(6) $\AA$ and the number of molecules per unit cell $\mathrm{z}=2$.

The density of the compound calculated from these values and from the molar mass of $344.90 \mathrm{~g}$ is $1.707 \mathrm{~g} \mathrm{~cm}^{-3}$. X-ray analysis shows that there are three crystallographically independent molecules in asymmetric unit. Two of these molecules are essentially identical structures and the third one is their enantiomer.

As shown in Figure 1, the chlorine atoms are in positions 3-exo, 5-exo, 6-exo, 9c, 10b, and 10c. This arrangement seems to offer minimum intramolecular interaction between the bulky chlorine atoms and results in a compact molecule, which allows efficient molecular packing in the crystal. The orientation of the chlorine atoms determined by X-ray analysis is convergent with the solution structure determined by NMR methods.

As shown in Table 1, almost all the $\mathrm{C}$-C bonds are slightly longer than the single bond value of $1.530(15) \AA .{ }^{18}$ The same applies to $\mathrm{C}-\mathrm{Cl}$ bond lengths, where the difference from the single bond $1.767(2) \AA^{18}$ is appreciably greater. These two findings are consistent with those reported for polychlorinated bornanes and for polychlorinated tricyclo compound. ${ }^{19-21}$ The mutual influence of the chlorine atoms in these compact polychlorinated molecules has the effect of stretching the bonds and increasing the size of the whole molecule. 


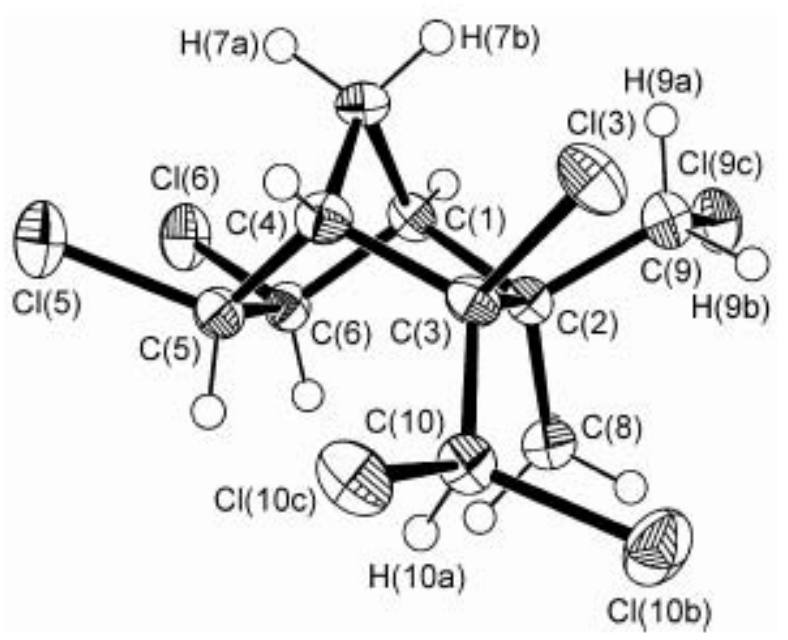

Figure 1. ORTEP view of 3-exo,5-exo,6-exo,9,10,10-hexachlorodihydrocamphene 2.

Table 1. Experimental and HF/6-31G* optimized bond lengths $(\AA)$ for 2. Selected experimental and $\mathrm{HF} / 6-31 \mathrm{G}^{*}$ optimized bond and torsion angles $\left(^{\circ}\right)$ for 2

\begin{tabular}{cccccc}
\hline Nuclei & Experimental & HF/6-31G* & Nuclei & Experimental & HF/6-31G* \\
\hline C1-C2 & $1.562(4)$ & 1.565 & C1-C2-C3 & $100.2(2)$ & 101.1 \\
C2-C3 & $1.614(4)$ & 1.615 & C2-C3-C4 & $103.3(2)$ & 102.0 \\
C3-C4 & $1.539(4)$ & 1.555 & C3-C4-C5 & $110.7(2)$ & 110.8 \\
C4-C5 & $1.536(4)$ & 1.548 & C4-C5-C6 & $103.1(2)$ & 103.2 \\
C5-C6 & $1.562(4)$ & 1.564 & C1-C2-C8 & $112.9(2)$ & 112.4 \\
C1-C6 & $1.527(4)$ & 1.540 & C2-C1-C6 & $109.4(2)$ & 110.7 \\
C1-C7 & $1.531(4)$ & 1.531 & C1-C2-C9 & $110.3(2)$ & 109.7 \\
C2-C8 & $1.530(4)$ & 1.543 & C4-C3-C10 & $115.0(3)$ & 114.1 \\
C2-C9 & $1.541(4)$ & 1.543 & C8-C2-C9 & $108.1(3)$ & 107.8 \\
C3-C10 & $1.532(4)$ & 1.545 & C1-C6-Cl6 & $110.4(2)$ & 110.3 \\
C4-C7 & $1.539(4)$ & 1.532 & C2-C9-C19 & $111.9(2)$ & 113.3 \\
C3-C13 & $1.819(3)$ & 1.818 & C4-C3-C13 & $105.04(19)$ & 105.5 \\
C5-C15 & $1.783(3)$ & 1.784 & C4-C5-C15 & $109.4(2)$ & 110.1 \\
C6-C16 & $1.800(3)$ & 1.789 & C3-C10-C110b & $111.7(2)$ & 113.7 \\
C9-C19 & $1.803(3)$ & 1.800 & C3-C10-C110c & $112.7(2)$ & 112.5 \\
C10-C110b & $1.786(3)$ & 1.777 & C1-C2-C9-C19 & $-70.0(3)$ & -67.8 \\
C10-C110c & $1.774(3)$ & 1.778 & C4-C3-C10-C110c & $-48.5(3)$ & -48.5 \\
\hline
\end{tabular}

\section{Analysis of the NMR spectra}

The ${ }^{1} \mathrm{H}$ chemical shift assignments for polychlorinated dihydrocamphenes are based on ${ }^{1} \mathrm{H},{ }^{1} \mathrm{H}$ coupling constants and two-dimensional DQF ${ }^{1} \mathrm{H},{ }^{1} \mathrm{H} \mathrm{COSY}^{22}$ experiments. The configuration of the compounds have been deduced by spatial proximities as indicated by ${ }^{1} \mathrm{H},{ }^{1} \mathrm{H}$ ROESY ${ }^{23}$ responses. The ${ }^{1} \mathrm{H}$ NMR parameters have been solved precisely with the PERCHit iterator ${ }^{24}$ 
under PERCH software. ${ }^{25}$ The ${ }^{1} \mathrm{H}$ chemical shifts and ${ }^{1} \mathrm{H},{ }^{1} \mathrm{H}$ coupling constants of compounds 19 are collected in Tables 2 and 3, respectively.

Since the crystal structure of hexachloro congener 2 is known, its ${ }^{1} \mathrm{H}$ NMR analysis is discussed first as an example. The ${ }^{1} \mathrm{H}$ NMR spectrum of 2 is shown in Figure 2A. The proton H10a gives rise a singlet at $\delta 6.09$. The two doublet of doublets, one at $\delta 4.51\left[{ }^{3} J(5,6)=6.73 \mathrm{~Hz}\right.$, $\left.{ }^{4} J(6,7 \mathrm{~b})=2.25 \mathrm{~Hz}\right]$, and the other one at $\delta 4.27\left[{ }^{3} J(5,6)=6.73 \mathrm{~Hz},{ }^{4} J(5,7 \mathrm{~b})=2.06 \mathrm{~Hz}\right]$ can be assigned to the two endo protons on $\mathrm{C} 6$ and $\mathrm{C} 5$, respectively.

The above-mentioned ${ }^{4} \mathrm{~J}$ couplings between $\mathrm{H} 5 / \mathrm{H} 6$ and $\mathrm{H} 7 \mathrm{~b}$ are typical for this type of bicyclic structures. $^{26}$

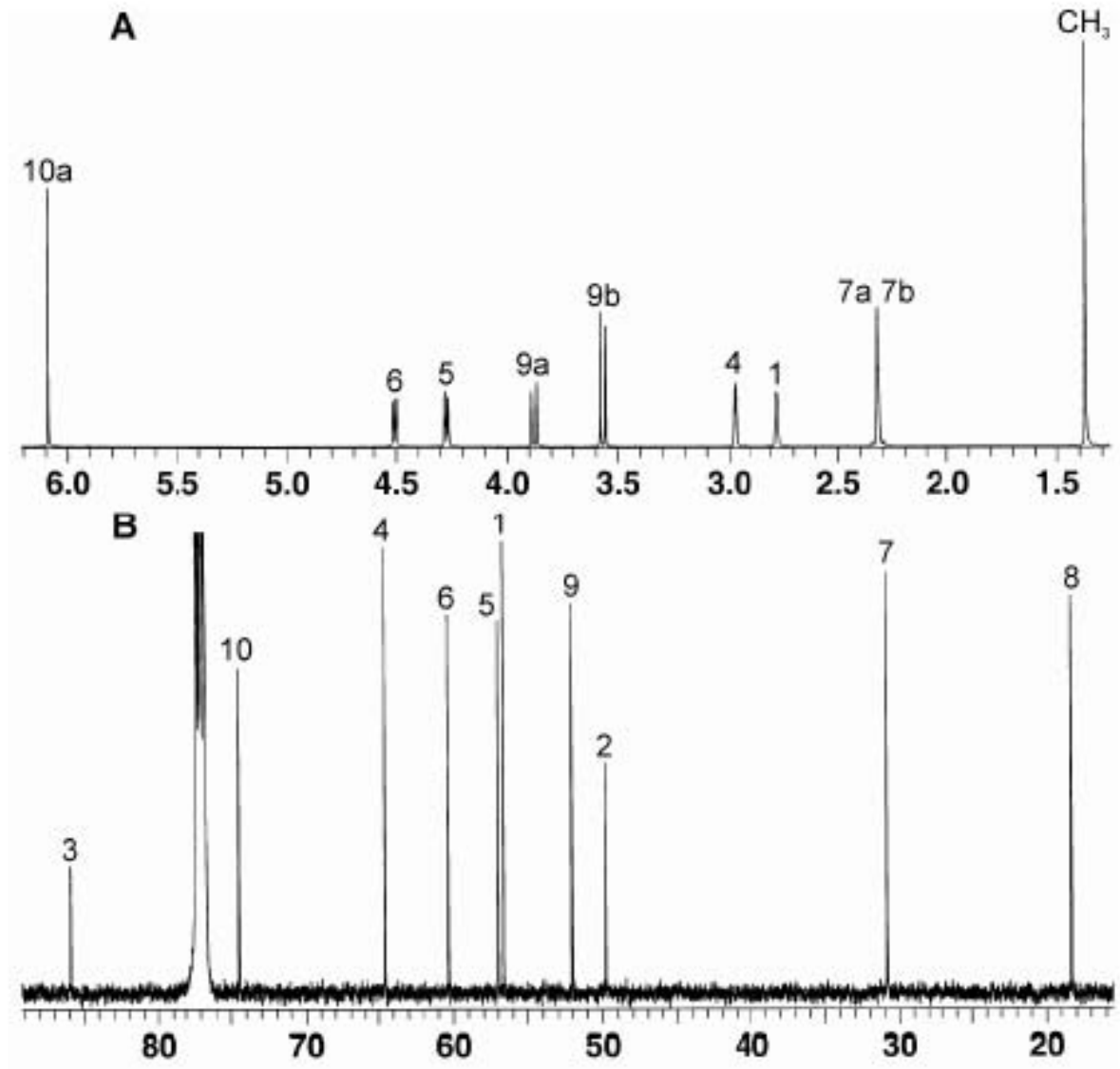

Figure 2. ${ }^{1} \mathrm{H} \quad$ (A) and ${ }^{13} \mathrm{C} \quad$ (B) $\mathrm{NMR}$ spectra of 3-exo,5-exo,6-exo,9,10,10hexachlorodihydrocamphene 2 . 
Table 2. ${ }^{1} \mathrm{H}$ NMR chemical shifts ( $\delta$, ppm from TMS) for 1-9

\begin{tabular}{ccccccccccc}
\hline Proton & 1 & 2 & 3 & 4 & 5 & 6 & $7^{a}$ & 8 & $9 \mathrm{a}^{b}$ & $9 \mathrm{~b}^{b}$ \\
\hline H1 & 2.53 & 2.78 & 2.44 & 2.73 & 3.01 & 2.50 & 2.84 & 3.98 & 3.41 & 2.65 \\
H4 & 3.00 & 2.97 & 3.53 & 3.50 & 3.05 & 3.57 & 3.08 & 3.04 & 3.63 & 3.56 \\
H5 & 4.28 & 4.27 & & & 4.32 & & 4.56 & 4.53 & & \\
H6 & 4.55 & 4.51 & 4.72 & 4.70 & 4.60 & 4.76 & 5.70 & & 4.91 & 4.75 \\
H7a & 2.32 & 2.33 & 2.46 & 2.46 & 2.31 & 2.51 & 2.46 & 2.60 & 2.57 & 2.55 \\
H7b & 2.33 & 2.31 & 2.71 & 2.68 & 2.29 & 2.72 & 2.38 & 2.23 & 2.53 & 3.43 \\
H8 & & 1.37 & & 1.55 & 1.56 & & & & & \\
H8a & 3.50 & & 3.81 & & & 3.71 & & 4.46 & 3.75 & 3.83 \\
H8b & 3.92 & & 4.06 & & & 4.52 & 6.65 & 4.89 & 4.91 & 4.48 \\
H9 & 1.47 & & 1.54 & & & & & & & \\
H9a & & 3.88 & & 3.93 & 6.10 & 3.99 & 3.99 & 6.53 & 6.46 & \\
H9b & & 3.57 & & 3.69 & & 4.02 & & & & \\
H9c & & & & & & & 4.18 & & & 6.47 \\
H10a & 6.01 & 6.09 & 6.83 & 6.90 & 5.99 & 6.79 & 7.10 & 6.07 & 6.85 & 6.87 \\
\hline
\end{tabular}

${ }^{a}$ Experiment at $-50^{\circ} \mathrm{C} .{ }^{b}$ Experiment at $0^{\circ} \mathrm{C}$.

The shift order of protons $\mathrm{H} 6$ and $\mathrm{H} 5$ is based on two-dimensional ROESY experiment. Inspection of the structure of 2 in Figure 1 reveals that $\mathrm{H} 10 \mathrm{a}$ is closer to $\mathrm{H} 5 \mathrm{(H}-\mathrm{H}$ distance 2.32(4) $\AA$ ) than to $\mathrm{H} 6$ ( $\mathrm{H}-\mathrm{H}$ distance 3.23(4) $\AA$ ). H10a would therefore be expected to have a stronger dipolar interaction with $\mathrm{H} 5$. This is indeed the case since the cross peak between H10a and $\mathrm{H} 5$ is intensive and that between $\mathrm{H} 10 \mathrm{a}$ and $\mathrm{H} 6$ is missing totally. In addition, the endo methyl group on $\mathrm{C} 2$ shows an intensive interaction with $\mathrm{H} 6$ (H-C distance 2.52(3) $\AA$ ), whereas a correlation with $\mathrm{H} 5$ is very weak (H-C distance 3.57(3) $\AA$ ).

The doublet of quartets at $\delta 3.88$, which has one large and one small coupling constant $\left[{ }^{2} J(9 a, 9 b)=-11.35 \mathrm{~Hz},{ }^{4} J(8,9 a)=0.81 \mathrm{~Hz}\right]$ and the doublet at $\delta 3.57\left[{ }^{2} J(9 a, 9 b)=-11.35 \mathrm{~Hz}\right]$ are both connected to $\mathrm{C} 9$. The lower field signal belongs unambiguously to H9a since a planar $\mathrm{W}$ pathway for long-range coupling exists only between the endo methyl group on C2 and H9a. The quartet at $\mathrm{H} 9 \mathrm{a}$ is in agreement with 3 equivalent protons on $\mathrm{C} 8$.

The two multiplets at $\delta 2.97\left[{ }^{4} J(1,4)=2.76 \mathrm{~Hz},{ }^{3} J(1,7 \mathrm{a})=1.64 \mathrm{~Hz},{ }^{3} J(1,7 \mathrm{~b})=1.52 \mathrm{~Hz}\right]$ and at $\delta 2.78\left[{ }^{4} J(1,4)=2.76 \mathrm{~Hz},{ }^{3} J(4,7 \mathrm{a})=1.62 \mathrm{~Hz},{ }^{3} J(4,7 \mathrm{~b})=1.53 \mathrm{~Hz}\right]$, respectively, must be attributed to $\mathrm{H} 4$ and $\mathrm{H} 1$. The electronegative chlorine substituents on $\mathrm{C} 3$ and $\mathrm{C} 5$ result in a downfield shift for $\mathrm{H} 4$ with respect to $\mathrm{H} 1$, which has only one chlorine atom in the near distance. The two multiplets of strongly coupled nuclei, one at $\delta 2.33\left[{ }^{2} J(7 \mathrm{a}, 7 \mathrm{~b})=-12.09 \mathrm{~Hz},{ }^{3} J(1,7 \mathrm{a})=\right.$ $\left.1.64 \mathrm{~Hz},{ }^{3} \mathrm{~J}(4,7 \mathrm{a})=1.62 \mathrm{~Hz}\right]$, and the other one at TM $2.31\left[{ }^{2} \mathrm{~J}(7 \mathrm{a}, 7 \mathrm{~b})=-12.09 \mathrm{~Hz},{ }^{4} \mathrm{~J}(6,7 \mathrm{~b})=2.25\right.$ $\left.\mathrm{Hz},{ }^{4} J(5,7 \mathrm{~b})=2.06 \mathrm{~Hz},{ }^{3} J(1,7 \mathrm{~b})=1.52 \mathrm{~Hz},{ }^{3} J(4,7 \mathrm{~b})=1.53 \mathrm{~Hz}\right]$ belongs to the pair of geminal protons on $\mathrm{C} 7$. Using the computer based analysis the lower field signal can be unambiguously assigned to $\mathrm{H} 7 \mathrm{a}$ since it has only three coupling constants in contrast to five coupling constants of $\mathrm{H} 7 \mathrm{~b}$. 
Table 3. ${ }^{\mathrm{n}} J\left({ }^{1} \mathrm{H},{ }^{1} \mathrm{H}\right)$ Coupling constants $(\mathrm{Hz})$ for $\mathbf{1 - 9}$

\begin{tabular}{ccccccccccc}
\hline Protons & 1 & 2 & 3 & 4 & 5 & 6 & $7^{a}$ & 8 & $9 \mathrm{a}^{b}$ & $9 \mathrm{~b}^{b}$ \\
\hline 1,4 & 2.79 & 2.76 & 2.74 & 2.71 & 3.01 & 2.90 & 2.73 & 3.11 & 3.02 & 2.92 \\
$1,7 \mathrm{a}$ & 1.69 & 1.64 & 1.63 & 1.51 & 1.63 & 1.63 & 1.41 & 1.56 & 1.66 & 1.67 \\
$1,7 \mathrm{~b}$ & 1.57 & 1.52 & 1.89 & 1.89 & 1.46 & 1.85 & 1.32 & 1.49 & 1.72 & 1.69 \\
$1,8 \mathrm{~b}$ & & & & & & & & -0.46 & & \\
$4,7 \mathrm{a}$ & 1.62 & 1.62 & 1.55 & 1.54 & 1.65 & 1.55 & 1.65 & 1.62 & 1.61 & 1.50 \\
$4,7 \mathrm{~b}$ & 1.52 & 1.53 & 1.47 & 1.47 & 1.57 & 1.50 & 1.44 & 1.73 & 1.49 & 1.64 \\
$4,9 \mathrm{c}$ & & & & & & & & & & 0.57 \\
5,6 & 6.81 & 6.73 & & & 6.86 & & 6.60 & & & \\
$5,7 \mathrm{~b}$ & 2.16 & 2.06 & & & 2.09 & & 2.13 & 3.19 & & \\
$6,7 \mathrm{~b}$ & 2.25 & 2.25 & 3.41 & 3.41 & 2.27 & 3.40 & 2.30 & & 3.33 & 3.59 \\
$7 \mathrm{a}, 7 \mathrm{~b}$ & -11.96 & -12.09 & -12.52 & -12.67 & -12.30 & -12.80 & -12.43 & -13.25 & -13.06 & -13.10 \\
$7 \mathrm{a}, 8 \mathrm{~b}$ & 0.74 & & 0.89 & & & 0.94 & 0.52 & 0.89 & 0.90 & 1.10 \\
$8,9 \mathrm{a}$ & & 0.81 & & 0.82 & 0.59 & & & & & \\
$8 \mathrm{a}, 8 \mathrm{~b}$ & -11.25 & & -11.24 & & & -11.74 & & -12.36 & -12.81 & -12.36 \\
$8 \mathrm{a}, 9$ & 1.25 & & 1.24 & & & & & & & \\
$8 \mathrm{a}, 9 \mathrm{a}$ & & & & & & 1.92 & & 1.90 & 2.01 & \\
$9 \mathrm{a}, 9 \mathrm{~b}$ & & -11.35 & & -11.32 & & -12.18 & & & & \\
$9 \mathrm{a}, 9 \mathrm{c}$ & & & & & & & -12.48 & & & \\
\hline
\end{tabular}

${ }^{a}$ Experiment at $-50^{\circ} \mathrm{C} .{ }^{b}$ Experiment at $0^{\circ} \mathrm{C}$

Finally, the high-field doublet at $\delta 1.37\left[{ }^{4} J(8,9 \mathrm{a})=0.81 \mathrm{~Hz}\right]$, which shows three times higher intensity compared with the other protons, can only be attributed to the endo methyl group on $\mathrm{C} 2$.

Compound $\mathbf{1}$ is a hexachloro congener, which has similar ${ }^{1} \mathrm{H}$ and ${ }^{13} \mathrm{C}$ spectral properties with those of compound 2. Inspection of ${ }^{1} \mathrm{H},{ }^{1} \mathrm{H}$ coupling constants and ROESY correlations reveals that the chloromethyl group on $\mathrm{C} 2$ is in an endo position and the methyl group is in an exo position. Thus, compound $\mathbf{1}$ has the same structure as $\mathbf{2}$ with the one difference that in compound 1 the orientations of the substituents on $\mathrm{C} 2$ are interchanged with respect to those of compound 2.

In compound 1 there is a long-range coupling between the bridge proton $\mathrm{H} 7 \mathrm{a}$ and $\mathrm{H} 8 \mathrm{~b}\left({ }^{5} \mathrm{~J}=\right.$ $0.74 \mathrm{~Hz}$ ), which follows a near planar zigzag pathway. This coupling is typical for all dihydrocamphenes examined with a $\mathrm{CH}_{2} \mathrm{Cl}$ or $\mathrm{CHCl}_{2}$ group in an endo configuration on $\mathrm{C} 2$.

Compounds 3, 4, and 5 are heptachloro congeners that have differences in chlorine substitution on $\mathrm{C} 5, \mathrm{C} 8$, and $\mathrm{C} 9$. In the compounds $\mathbf{3}$ and $\mathbf{4}$, the additional chlorine is attached at the endo position of C5. This is confirmed by the ROESY spectrum of $\mathbf{3}$ and $\mathbf{4}$, in which H10a shows no correlation with the low-field doublet at $c a . \delta 4.7$. Instead, this doublet shows an intensive interaction with H8a in $\mathbf{3}$ and with the endo methyl group in $\mathbf{4}$.

In compound 5, the additional chlorine atom is attached on C9. The proton on C9 shows a 
long-range coupling to the endo methyl group on $\mathrm{C} 2\left({ }^{4} \mathrm{~J}=0.59 \mathrm{~Hz}\right)$. This is possible only if there is a planar $\mathrm{W}$ pathway between these two spins. Therefore, the proton must be in position H9a.

Compound $\mathbf{6}$ is an octachloro and compound $\mathbf{8}$ is a nonachloro congener, respectively, both of which one of the ring carbons (C5 or C6) is doubly chlorinated. According to ROESY correlations, compound $\mathbf{6}$ has two chlorine substituents on C5 whereas in compound 8 the two chlorines are attached to C6. Compound $\mathbf{8}$ is the only dihydrocamphene examined in which the long-range coupling between $\mathrm{H} 1$ and $\mathrm{H} 8 \mathrm{~b}\left({ }^{4} \mathrm{~J}=-0.46 \mathrm{~Hz}\right)$ is detectable.

At $30^{\circ} \mathrm{C}$ the ${ }^{1} \mathrm{H}$ NMR spectrum of octachloro compound 7 and that of nonachloro congener 9 show significant broadening of the signals of several protons. These poorly 12 resolved spectra are attributed to the existence of several conformers in equilibrium due to the rotation of chloromethyl and dichloromethyl groups. Therefore, the ${ }^{1} \mathrm{H}$ spectra for $\mathbf{7}$ and $\mathbf{9}$ have been recorded in the temperature range $-60^{\circ} \mathrm{C}$ to $+60^{\circ} \mathrm{C}$, at intervals of $10^{\circ} \mathrm{C}$.

The ${ }^{1} \mathrm{H}$ spectrum of compound 7 at $30^{\circ} \mathrm{C}$ shows broadening of the signals of dichloromethyl protons and of protons $\mathrm{H} 1$ and $\mathrm{H} 6$ at $\delta 7.10, \delta 6.65, \delta 5.70$, and $\delta 2.84$. This broadening gets weaker at elevated temperature and disappears at $-50^{\circ} \mathrm{C}$. At lowered temperature no sign of another conformation appear which means that the most stable conformation is predominant $(>$ 90\%) in equilibration mixture. The ${ }^{1} \mathrm{H}$ NMR parameters of compound 7 have been deduced from the spectrum measured at $-50^{\circ} \mathrm{C}$ and the favourable conformation of 7 is based on ROESY experiment at the same temperature. The preferred conformation of 7 , based on the NMR analysis, is identical with that obtained from the theoretical calculations performed at the HF/6$31 \mathrm{G}^{*}$ level.

The ${ }^{1} \mathrm{H}$ spectrum of compound 9 at $30^{\circ} \mathrm{C}$ shows two sets of broadened signals without fine structure. At elevated temperature, only one set of signals is visible with weaker broadening. At $0^{\circ} \mathrm{C}$ broadening disappears and the fine structure of both sets of signals becomes clearly visible. Therefore, at $0^{\circ} \mathrm{C}$ this compound exists in two conformations that are contributing in the proportion of 71 (9a) to 29 (9b). On NMR time scale rotation is slow at $30^{\circ} \mathrm{C}$, fast at $60^{\circ} \mathrm{C}$, and no rotation is observed at $0^{\circ} \mathrm{C}$. The NMR parameters and conformational analysis of compound 9 are based on experiments performed at $0^{\circ} \mathrm{C}$.

The only difference between the major conformation 9a and the minor conformation $\mathbf{9 b}$ is the orientation of the chlorine atoms on C9. In conformer 9a, the strong long-range coupling between $\mathrm{H} 8 \mathrm{a}$ and proton on $\mathrm{C} 9\left({ }^{4} \mathrm{~J}=2.01 \mathrm{~Hz}\right)$ is possible only if there is a 13 planar $\mathrm{W}$ pathway between these two spins. Therefore, in this conformation the proton on C9 must be in position H9a. In conformer 9b above-mentioned W coupling disappears. Instead, there emerges a longrange coupling between $\mathrm{H} 4$ and proton on $\mathrm{C} 9\left({ }^{5} \mathrm{~J}=0.57 \mathrm{~Hz}\right)$. This indicates that in $\mathbf{9 b}$ the proton on $\mathrm{C} 9$ must be in position $\mathrm{H} 9 \mathrm{c}$ or, otherwise, a near planar zigzag pathway for long-range coupling is not possible. This finding is supported by the observation that $\mathrm{H} 7 \mathrm{~b}$ experiences a significant downfield shift because of spatial proximity of electronegative chlorine atom in position C19a.

Instead, H4 experiences a significant upfield shift indicating that electronegative atom is moved away from its spatial proximity. The two conformations of 9, based on the NMR studies, are completely consistent with those obtained from the geometry optimizations performed at the 
HF/6-31G* level.

The PFG ${ }^{1} \mathrm{H},{ }^{13} \mathrm{C}$ HMQC ${ }^{27-29}$ correlation map provides an assignment of the ${ }^{13} \mathrm{C} \mathrm{NMR}$ chemical shifts of protonated carbons, whereas the quaternary carbons are unambiguously assigned by performing PFG ${ }^{1} \mathrm{H},{ }^{13} \mathrm{C}$ HMBC ${ }^{30}$ experiments. The ${ }^{13} \mathrm{C}$ chemical shifts for $\mathbf{1 - 9}$ are given in Table 4.

Table 4. Experimental vs. B3LYP/6-311G* predicted $^{a 13} \mathrm{C}$ NMR chemical shifts $(\delta$, ppm from TMS) for 1-9

\begin{tabular}{|c|c|c|c|c|c|c|c|c|c|c|}
\hline Compound & $\mathrm{C} 1$ & $\mathrm{C} 2$ & $\mathrm{C} 3$ & $\mathrm{C} 4$ & $\mathrm{C} 5$ & C6 & $\mathrm{C} 7$ & $\mathrm{C} 8$ & C9 & $\mathrm{C} 10$ \\
\hline 1 & 58.5 & 52.1 & 86.2 & 64.7 & 57.1 & 59.9 & 29.9 & 47.4 & 25.1 & 73.9 \\
\hline 1 (calc.) & 57.4 & 55.3 & 85.8 & 64.0 & 57.3 & 59.2 & 30.5 & 46.5 & 24.5 & 74.2 \\
\hline 2 & 56.6 & 49.8 & 85.9 & 64.5 & 57.0 & 60.3 & 30.8 & 18.3 & 52.0 & 74.4 \\
\hline 2 (calc.) & 55.8 & 52.9 & 85.6 & 63.7 & 57.2 & 59.6 & 31.3 & 19.3 & 49.8 & 74.6 \\
\hline 3 & 58.8 & 52.0 & 88.6 & 71.4 & 91.6 & 70.5 & 34.5 & 47.6 & 25.0 & 74.5 \\
\hline 3 (calc.) & 57.1 & 55.1 & 88.0 & 70.3 & 93.1 & 68.8 & 34.8 & 46.6 & 24.4 & 74.8 \\
\hline 4 & 56.5 & 49.7 & 88.5 & 71.3 & 91.6 & 70.2 & 35.5 & 18.8 & 51.9 & 75.3 \\
\hline 4 (calc.) & 55.3 & 52.7 & 87.9 & 70.3 & 93.0 & 68.6 & 35.5 & 19.7 & 49.7 & 75.3 \\
\hline 5 & 59.6 & 57.8 & 83.7 & 66.0 & 57.0 & 60.2 & 29.9 & 13.1 & 78.6 & 73.7 \\
\hline 5 (calc.) & 59.0 & 60.5 & 83.4 & 64.9 & 57.1 & 59.4 & 30.3 & 14.3 & 77.4 & 73.7 \\
\hline 6 & 57.6 & 56.2 & 86.6 & 71.7 & 91.1 & 70.1 & 34.3 & 43.0 & 48.0 & 73.1 \\
\hline 6 (calc.) & 53.6 & 57.0 & 89.3 & 70.0 & 92.6 & 69.2 & 35.1 & 45.0 & 48.6 & 74.7 \\
\hline 7 & 58.5 & 62.0 & 86.3 & 65.0 & 55.8 & 58.6 & 31.3 & 74.2 & 52.1 & 73.0 \\
\hline 7 (calc.) & 57.7 & 65.3 & 85.8 & 64.0 & 55.7 & 57.8 & 31.8 & 75.6 & 50.6 & 73.1 \\
\hline 8 & 64.5 & 61.2 & 85.5 & 65.6 & 68.6 & 92.5 & 32.3 & 41.7 & 77.8 & 73.5 \\
\hline 8 (calc.) & 63.7 & 64.3 & 85.2 & 64.1 & 67.6 & 93.3 & 32.8 & 41.1 & 76.7 & 74.0 \\
\hline $9 \mathrm{a}$ & 57.7 & 60.6 & 88.2 & 72.0 & 90.9 & 70.7 & 33.7 & 41.1 & 76.2 & 73.2 \\
\hline 9a (calc.) & 56.6 & 63.8 & 87.9 & 70.7 & 92.4 & 68.9 & 33.9 & 40.8 & 75.1 & 73.4 \\
\hline $9 b$ & 58.0 & 60.7 & 85.2 & 70.8 & 91.5 & 70.8 & 35.0 & 44.7 & 73.1 & 72.8 \\
\hline $9 \mathrm{~b}$ (calc.) & 56.7 & 64.1 & 85.0 & 69.6 & 92.9 & 69.1 & 35.3 & 44.5 & 73.2 & 73.1 \\
\hline
\end{tabular}

${ }^{a}$ From equation 2 .

The ${ }^{13} \mathrm{C}$ NMR data of the dihydrocamphenes, registered at $30^{\circ} \mathrm{C}$, confirm the proposed structures. The spectra for compounds 1-6 and $\mathbf{8}$ show 10 sharp signals according to a single conformation (see Figure $2 \mathrm{~B}$ for an example). In the case of compound 7 the ${ }^{13} \mathrm{C}$ NMR spectrum shows sharp signals for nine of the carbons, while C9 present signal of low intensity and of broadened linewidth. In the case of compound 9 the ${ }^{13} \mathrm{C} N \mathrm{NM}$ spectrum contain two sets of signals with different intensities, enabling assignment of the chemical shifts to conformers 9a and 9b. The largest chemical shift difference. $\delta$ between 9a and 9b is observed for C8, $3.6 \mathrm{ppm}$. The other significant $\Delta \delta$ involve $\mathrm{C} 9$ and $\mathrm{C} 3$, for which 3.1 and $3.0 \mathrm{ppm}$ differences, respectively, have been measured. The smallest chemical shift difference, $0.1 \mathrm{ppm}$, concern $\mathrm{C} 2$ and $\mathrm{C} 6$. 


\section{Quantum mechanical calculations}

Full geometry optimizations have been performed at the $a b$ initio HF/6-31G* level for a comparison with the conformational and structural properties obtained from the NMR-and X-ray experiments. The orientation of the chlorine atoms is equivalent with those obtained from the NMR analysis and the optimized geometry of $\mathbf{2}$ is in excellent agreement with the crystal structure, as shown in Figure 3. In comparison with the Xray data of 2, values for the C-C bond lengths calculated at the $\mathrm{HF} / 6-31 \mathrm{G}^{*}$ level are too long while the $\mathrm{C}-\mathrm{Cl}$ bond lengths are too short, as shown in Table 1. Generally, the bond angles are reproduced within the deviation of one degree. From the above it is evident that the structures of the polychlorinated dihydrocamphenes can be accurately reproduced at the $\mathrm{HF} / 6-31 \mathrm{G}^{*}$ level for the NMR calculation purposes.

$\mathrm{HF} / 6-31 \mathrm{G}^{*}$ calculations indicate that only a single conformer is contributing significantly in the case of compound 7 (at $223 \mathrm{~K}$ ). For compound 9, HF/6-31G* predicts that the two rotamers, 9a and 9b, pictured in Figure 3 are contributing in the proportion of 59.3 (9a) to 40.7 (9b) at 273 $\mathrm{K}$. These observations are in very good agreement with the NMR experiments.

Rotation barriers of 7and 9 have been characterized only with the semiempirical AM1 method ${ }^{15}$ due to the considerable computational cost required for corresponding ab initio calculations. The barriers for chloromethyl and dichloromethyl group rotations have been computed in steps of $10^{\circ}$, and the potential energy curves have been visualized with the MATLAB program package.

For the rotation about the $\mathrm{C} 2 / \mathrm{C} 8, \mathrm{C} 2 / \mathrm{C} 9$, and $\mathrm{C} 3 / \mathrm{C} 10$ bonds, three local minima of energy are found, as shown in Figure 4. The torsional barriers in Figure 4 are referenced to their respective global minimum for ease of comparison.

For compound 9, the a and b conformers are clearly visible (Figures 4A-C). As expected, conformation 9a (heat of formation $-188.78 \mathrm{~kJ} \mathrm{~mol}^{-1}$ ), with the chlorine atoms in $8 \mathrm{c}, 9 \mathrm{~b}, 9 \mathrm{c}, 10 \mathrm{~b}$, and $10 \mathrm{c}$ positions, is predicted to be slightly more stable than conformation $\mathbf{9 b}$ (heat of formation

$-183.89 \mathrm{~kJ} \mathrm{~mol}^{-1}$ ). The barrier to rotation from the more stable a conformation to the less stable b conformation is found to be ca. $72.2 \mathrm{~kJ} \mathrm{~mol}^{-1}$ and the Boltzmann distribution to be $89.6 \%$ (a) and $10.4 \%$ (b). These observations are qualitatively in agreement with the NMR experiments discussed above.

In the case of 7, two stable conformations are again found (Figures 4D-F). In this case, the second conformation (chlorines in 8a, 8b, 9c, 10b, and 10c positions; heat of formation -183.89 $\mathrm{kJ} \mathrm{mol}^{-1}$ ) is in energy only $6.52 \mathrm{~kJ} \mathrm{~mol}^{-1}$ higher than the optimal conformer (chlorines in $8 \mathrm{a}, 8 \mathrm{c}$, $9 \mathrm{~b}, 10 \mathrm{~b}$, and $10 \mathrm{c}$ positions; heat of formation $-190.41 \mathrm{~kJ} \mathrm{~mol}^{-1}$ ). However, no evidence of the other stable conformation is found at the NMR and $a b$ initio data. Reoptimization at the HF/6$31 \mathrm{G}^{*}$ level resulted in considerably larger energy difference of $14.7 \mathrm{~kJ} \mathrm{~mol}^{-1}$. Therefore, there is no need to consider the other conformer.

From the above it is evident that although the energy differences for the various conformations leave a lot to be desired, the AM1 method is capable of the qualitatively accurate prediction of the rotation barriers for the model polychlorinated dihydrocamphenes. ${ }^{17}$ 

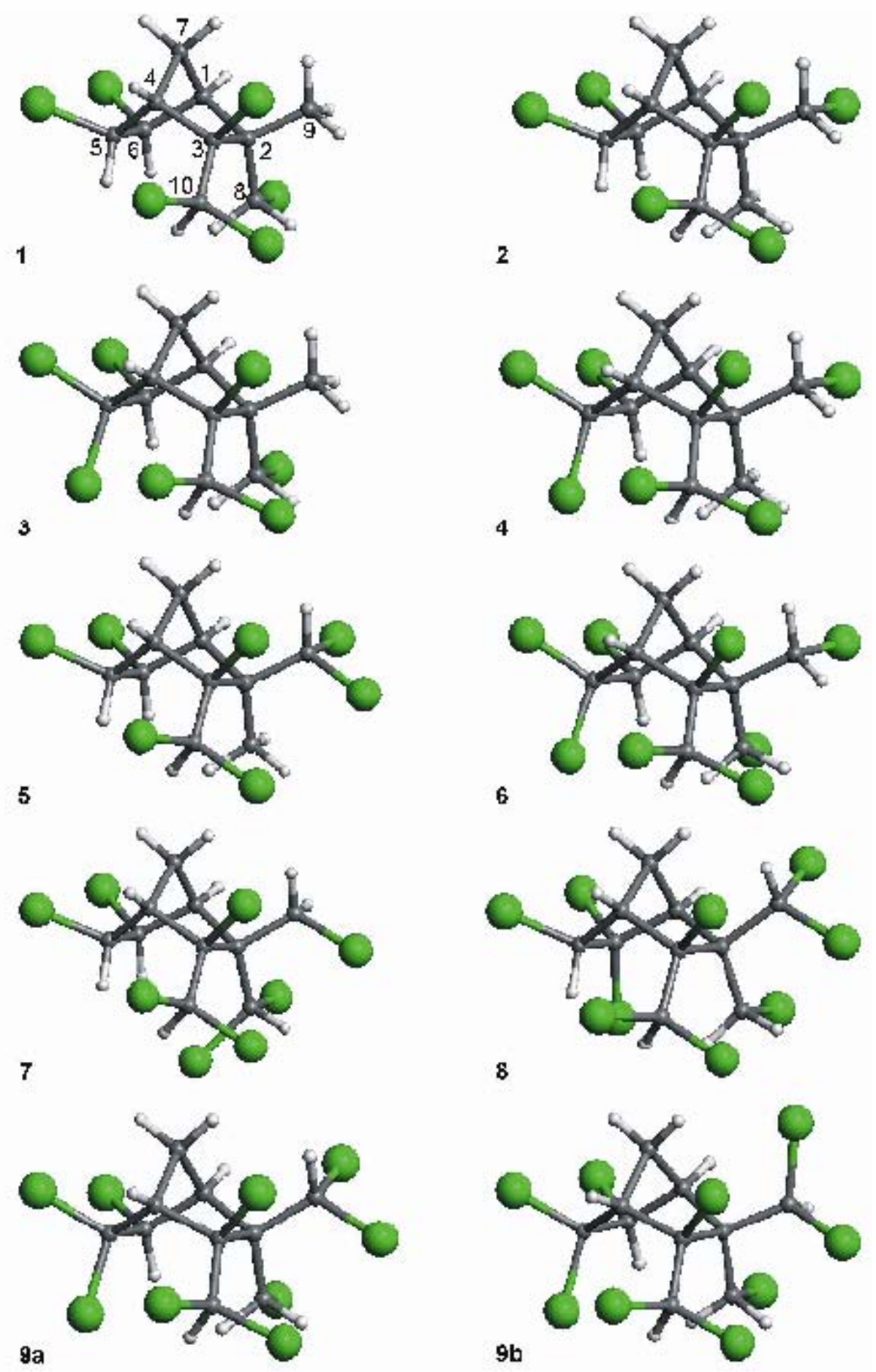

Figure 3. HF/6-31G* optimized geometries of dihydrocamphenes 1-9. ${ }^{16}$ 

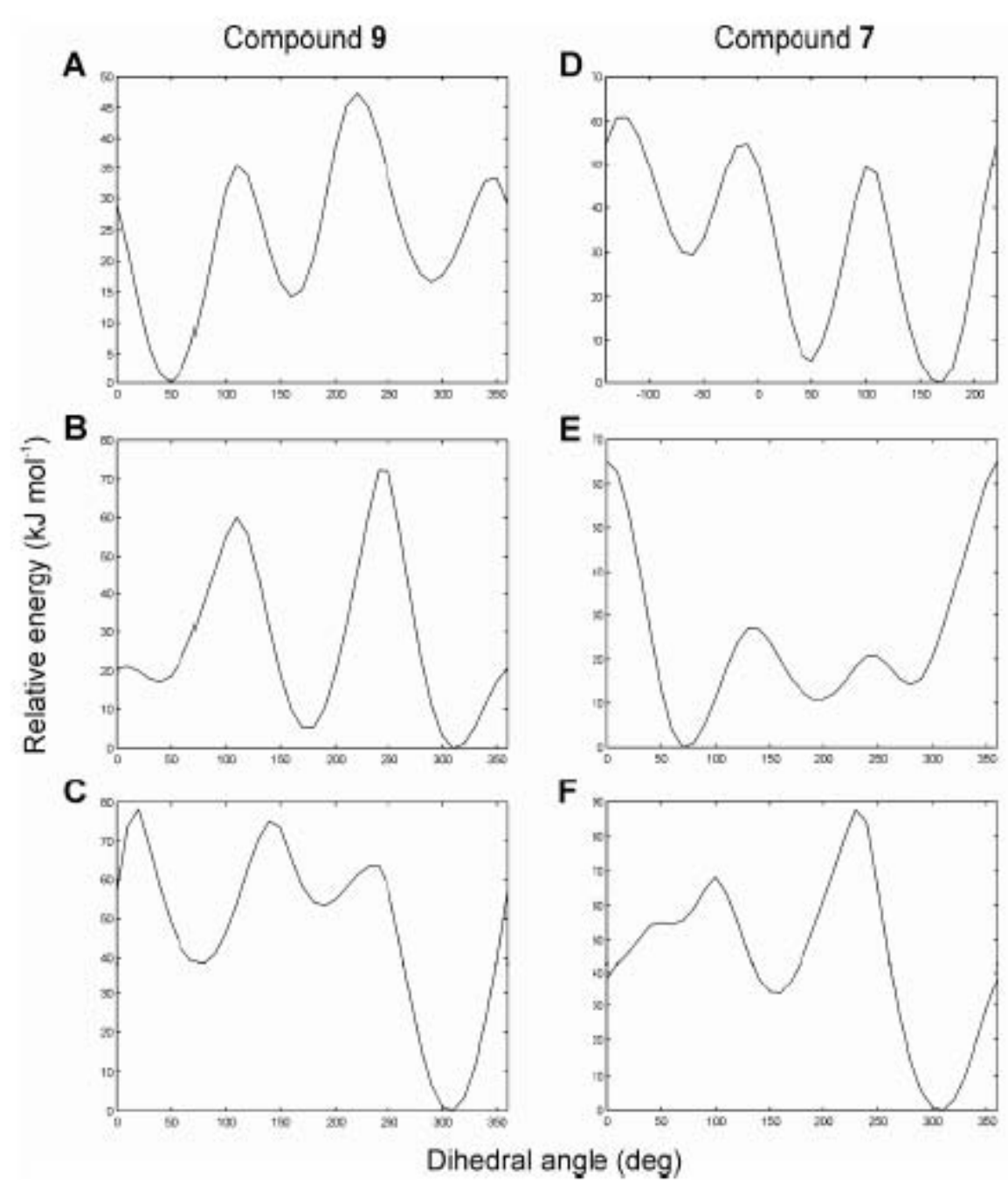

Figure 4. AM1 calculated rotation barriers for compounds 9 (left) and 7 (right). A and D: rotation about the $\mathrm{C} 8 / \mathrm{C} 2$ bond, $\mathbf{B}$ and $\mathbf{E}$ : rotation about the $\mathrm{C} 9 / \mathrm{C} 2$ bond, and $\mathbf{C}$ and $\mathbf{F}$ : rotation about the $\mathrm{C} 10 / \mathrm{C} 3$ bond.

The absolute shieldings for dihydrocamphenes and tetramethylsilane (TMS) have been obtained using the GIAO ${ }^{17}$ method at the DFT B3LYP/6-311G* level of theory and HF/6-31G* optimized geometries. The predicted ${ }^{13} \mathrm{C}$ chemical shifts are derived from equation $\delta=\sigma_{0}-\sigma$, where $\delta$ is the chemical shift, $\sigma$ is the absolute shielding, and $\sigma_{0}$ is the absolute shielding of the standard (in this case, TMS). ${ }^{18}$

In general, the DFT GIAO predictions are considered to provide reliable values with relatively small basis set and with reasonable computational efforts. Preliminary calculations (data not shown), employing 2,2,3-exo,5-endo,6-exo,8,9,10- octachlorobornane (2,2,3-exo,5endo,6-exo-pentachloro-1,7,7-tris-chloromethylbicyclo[2.2.1]heptane) as a test molecule, confirmed this clearly. The correlation coefficient between experimental ${ }^{8}$ and calculated 
(GIAO/B3LYP/6-311G*//6-31G*) values for the test molecule was 0.9961. The testing of different basis sets indicated that geometry optimization at the HF/6-31G* level is appropriate for this family of molecules. Instead, the use of smaller basis sets such as $3-21 \mathrm{G}^{*}$ was clearly detrimental.

It revealed that B3LYP predicts ${ }^{13} \mathrm{C}$ shifts which, in general, are too deshielded. However, the overall correlation between calculated and experimental chemical shift values is good, as shown in Figure 5. The largest deviations lie in the range of 60-80 ppm, even though the largest absolute errors occur with highly chlorinated carbons. The worst cases by far are the doubly chlorinated ring carbons $\mathrm{C} 5$ and $\mathrm{C} 6$, for which the chemical shifts are predicted with an error, that range from 18.1 to $18.7 \mathrm{ppm}$. The second worst case is doubly chlorinated $\mathrm{C} 10$, for which experiment and theory disagree by $14.2-15.9 \mathrm{ppm}$. In the range of 55-70 ppm there are some false assignments present for each dihydrocamphene except 2 . Unfortunately, we have no sound explanation to offer for this behaviour. It is possible that the basis set used is not large enough to consider the influence of chlorines.

A comparison of the calculated and experimental data yielded the following linear correlation between $\delta_{\text {obs }}$ and $\delta_{\text {calc }}$ :

$$
\delta_{\text {obs }}=0.791 \delta_{\text {calc }}+6.817
$$

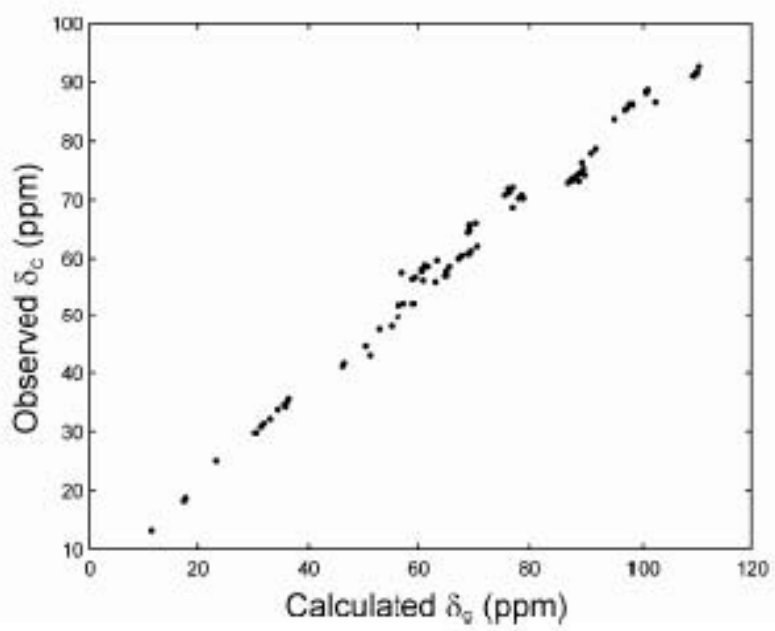

Figure 5. Correlation between experimental and theoretical ${ }^{13} \mathrm{C}$ chemical shifts.

with a standard error of $2.314 \mathrm{ppm}$ and a squared correlation coefficient $r^{2}=0.985$ (Figure 5). We improved the predictive ability of the model by adding an indicator variable $\mathrm{N}_{\mathrm{Cl}}$ (the number of chlorine atoms attached to each carbon) to the regression equation. Consequently, an adjusted correlation between $\delta_{\text {obs }}$ and $\delta_{\text {calc }}$ is obtained, expressed by the following equation:

$$
\delta_{\text {obs }}=0.862 \delta_{\text {calc }}-3.170 \mathrm{~N}_{\mathrm{Cl}}+4.316
$$

The standard error is decreased to $1.435 \mathrm{ppm}$ and the squared correlation coefficient is 
improved to 0.994 . Furthermore, the largest absolute error is only $-4.0 \mathrm{ppm}$. Most of the false assignments are absent and the chemical shift variations associated with different conformations of 9a and 9b are described correctly. As shown in Table 4, it is evident that GIAO B3LYP/6$311 \mathrm{G}^{*}$ method with equation 2 is capable of the accurate prediction of carbon chemical shifts for selected polychlorinated dihydrocamphenes using the $\mathrm{HF} / 6-31 \mathrm{G}^{*}$ optimized structures as geometry input.

\section{Experimental Section}

\section{Compounds}

3-ехо,5-ехо,6-ехо, 8, 10,10-hexachlorodihydrocamphene (3-ехо,5-ехо,6-ехо-trichloro-2-endochloromethyl-3-endo-dichloromethyl-2-exo-methyl-bicyclo[2.2.1]heptane) 1, 3-exo,5-exo,6exo,9,10,10-hexachlorodihydrocamphene (3-ехо,5-ехо,6-exo-trichloro-2-exo-chloromethyl-3endo-dichloromethyl-2-endo-methyl-bicyclo[2.2.1]heptane) 2, 3-exo,5,5,6-exo,8,10,10-heptachlorodihydrocamphene (3-exo,5,5,6-exo-tetrachloro-2-endo-chloromethyl-3-endo-dichloromethyl-2-exo-methyl-bicyclo[2.2.1]heptane) 3, 3-exo,5,5,6-exo,9,10,10-heptachlorodihydrocamphene (3-exo,5,5,6-exo-tetrachloro-2-exochloromethyl-3-endo-dichloromethyl-2-endomethyl-bicyclo[2.2.1]heptane) 4, 3-ехо,5-ехо,6-ехо,9,9,10,10-heptachlorodihydrocamphene (3exo,5-exо,6-exo-trichloro-2-exo,3-endo-bis-dichloromethyl-2-endo-methyl-bicyclo[2.2.1] heptane) 5, 3-ехо,5,5,6-ехо,8,9,10,10-octachlorodihydrocamphene (3-exo,5,5,6-exo-tetrachloro-2,2bischloromethyl-3-endo-dichloromethyl-bicyclo[2.2.1]heptane) 6, 3-exo,5-exo,6-exo,8,8,9,10,10octachlorodihydrocamphene (3-exo,5-exo,6-exo-trichloro-2-exochloromethyl-2-endo,3-endo-bisdichloromethyl-bicyclo[2.2.1]heptane) 7, 3-ехо,5-exo,6,6,8,9,9,10,10-nonachlorodihydrocamphene (3-exo,5-exo,6,6-tetrachloro-2-endochloromethyl-2-exo,3-endo-bis-dichloromethyl-bicyclo[2.2.1]heptane) 8, 3-exo,5,5,6-exo,8,9,9,10,10-nonachlorodihydrocamphene (3-exo,5,5,6exo-tetrachloro-2-endochloromethyl-2-exo,3-endo-bis-dichloromethyl-bicyclo[2.2.1]heptane) 9.

\section{Synthesis and isolation}

All compounds were prepared by chlorination of lower chlorinated monoterpenes, followed by fractionation on silica gel with hexane as eluent. ${ }^{9,}{ }^{31-35}$ Compounds $\mathbf{1}, \mathbf{2}$, and $\mathbf{5}$ were obtained as by-products from preparation of 2,2,5-endo,6-exo,8,9,10-heptachlorobornane (2,2,5-endo,6-exotetrachloro-1,7,7-tris-chloromethylbicyclo[2.2.1]heptane) by fractionation of chlorinated camphene with an average content of chlorine 6.5 atoms in a molecule. ${ }^{33,34}$ Compounds 3, 4, 6, and 7 were prepared by fractionation of chlorinated 5-exo,10-dichlorocamphene, average content of chlorine 7.5 atoms in a molecule. ${ }^{9}$ Compounds $\mathbf{8}$ and $\mathbf{9}$ were prepared by fractionation of perchlorinated 5-exo,10-dichlorocamphene, average content of chlorine 9.5 atoms in a molecule. ${ }^{35}$ As a rule, several successive crystallizations from different solvents were a way to final purification.

Relative GC retention times, determined against 2,2,5,5,8,9,9,10,10-nonachlorobornane 
(2,2,5,5-tetrachloro-7-chloromethyl-1,7-bis-dichloromethyl-bicyclo[2.2.1]heptane), are summarized in Table 5. This compound was chosen because, according to our experience, it is not interfered by co-elution. The GC experiments were carried out using a Varian 3700 gas chromatograph. The GC was equipped with a $53 \mathrm{~m}$ DB-5 capillary column $(0.25 \mathrm{~mm}$ i.d., $0.1 \mu \mathrm{m}$ film thickness) with nitrogen as the carrier gas $\left(1.33 \mathrm{ml} \mathrm{min}^{-1}\right)$. The splitless injection port and electron capture detector was maintained at $250^{\circ} \mathrm{C}$ and $300^{\circ} \mathrm{C}$, respectively. Nitrogen was used as the make-up gas $\left(40 \mathrm{ml} \mathrm{min}{ }^{-1}\right)$. The oven temperature was first held $2 \mathrm{~min}$ at $160^{\circ} \mathrm{C}$ followed by a ramp to $280^{\circ} \mathrm{C}$ at $20^{\circ} \mathrm{C} \mathrm{min}^{-1}$, with a final hold of $10 \mathrm{~min}^{31,32}$

Table 5. GC retention times (RRT) of 1-9 relative to 2,2,5,5,8,9,9,10,10-nonachlorobornane

\begin{tabular}{cccccccccc}
\hline Compound & 1 & 2 & 3 & 4 & 5 & 6 & 7 & 8 & 9 \\
\hline RRT & 0.8053 & 0.8191 & 0.8066 & 0.8335 & 0.9129 & 0.9422 & 0.9752 & 1.0416 & 1.0248 \\
\hline
\end{tabular}

\section{X-ray analysis}

Colourless crystals of suitable size $(0.10 \cdot 0.10 \cdot 0.30 \mathrm{~mm})$ and quality for x-ray crystallographic analysis was obtained by slow evaporation from $\mathrm{CDCl}_{3}$. The crystal structure data were recorded with Nonius KappaCCD diffractometer using graphite monochromatised MoK radiation $(\lambda=$ $0.71073 \AA$ ) [oscillation angle of $1^{\circ}$ and exposure time $2 \cdot 120 \mathrm{sec}$ ] and the temperature of $173.0 \pm$ $0.1 \mathrm{~K}$. The data were processed by DENZO-SMN. ${ }^{36}$ The structures were solved by direct methods (SHELXS-97) ${ }^{37}$ and refined on $F^{2}$ (SHELXL-97). ${ }^{38}$

C10H12Cl6: $\mathrm{Mr}=344.90$, triclinic, space group P -1 (no. 2), $a=7.1965(2), b=13.8275(5), c=$ 20.7769(6) $\AA, V=2012.8(1) \AA^{3}, Z=6, D_{\mathrm{c}}=1.707 \mathrm{~g} \mathrm{~cm}^{-3}, F(000)=1044.10812$ reflections collected in the $\theta$-range $3.63-25.02^{\circ}$ and used for refinement (5892 $\left.I>2 \sigma I\right)$. Reflections were corrected for Lorenz polarisation effects. Absorption correction was made but not applied for final refinement $\left(\mu\left(\mathrm{MoK}_{\alpha}\right)=1.249 \mathrm{~mm}^{-1}\right)$. The hydrogen atoms were located from the difference Fourier map and refined with isotropic temperature factors. The final $R$-values were $R 1=0.0392$ and $\mathrm{w} R 2=0.0819$ for 5892 unique data with $I>2 \sigma$ and $\mathrm{R} 1=0.0522$ and $\mathrm{w} R 2=0.0871$ for all data and 577 parameters: $\mathrm{w}=1 /\left[\sigma^{2}\left(\mathrm{~F}_{\mathrm{o}}{ }^{2}\right)+2.01 * \mathrm{P}\right]$ where $\mathrm{P}=\left(\operatorname{Max}\left(\mathrm{F}_{\mathrm{o}}{ }^{2}, 0\right)+2 * \mathrm{~F}_{\mathrm{c}}{ }^{2}\right) / 3$ and GooF $=1.098$. The final difference map displayed no electron density higher than $0.35 \mathrm{e} . \AA^{-3}$.

\section{NMR spectroscopy}

All NMR experiments were performed on dilute $\mathrm{CDCl}_{3}$ solutions at $30^{\circ} \mathrm{C}$ unless otherwise stated. For compounds 7 and $9{ }^{1} \mathrm{H}$ spectra were recorded in the temperature range -60 to $+60^{\circ} \mathrm{C}$, at intervals of $10^{\circ} \mathrm{C}$. In addition to measurements at $30^{\circ} \mathrm{C}$, ROESY spectrum for 7 and 9 were recorded at $-50^{\circ} \mathrm{C}$ and $0^{\circ} \mathrm{C}$, respectively. NMR spectrometer used was Bruker Avance DRX 500 equipped with a z-gradient accessory and an inverse (or a direct detection) $5 \mathrm{~mm}$ diameter probehead working at $500.13 \mathrm{MHz}$ for ${ }^{1} \mathrm{H}$ and $125.77 \mathrm{MHz}$ for ${ }^{13} \mathrm{C}$, respectively. The chemical shifts were referenced to the signal of $0.03 \%$ internal TMS.

The chemical shift assignments are based on two-dimensional DQF ${ }^{1} \mathrm{H},{ }^{1} \mathrm{H} C O S Y,{ }^{22} \mathrm{PFG}{ }^{1} \mathrm{H}$, ${ }^{13} \mathrm{C} \mathrm{HMQC},{ }^{27-29}{ }^{1} \mathrm{H},{ }^{13} \mathrm{C} \mathrm{HMBC},{ }^{30}$ and ${ }^{1} \mathrm{H},{ }^{1} \mathrm{H}$ ROESY ${ }^{23}$ measurements. Detailed acquisition and 
processing parameters are available by E. K. on request. The ${ }^{1} \mathrm{H}$ NMR spectral analysis was performed with the PERCHit iterator ${ }^{24}$ under PERCH software $^{25}$ using a Pentium II $233 \mathrm{MHz}$ personal computer. The total lineshape fitting option of the PERCHit iterator was used for the final refinement of the result.

\section{Quantum mechanical calculations}

Full geometry optimizations were done at the $a b$ initio $\mathrm{HF} / 6-31 \mathrm{G}^{*}$ level. Rotation barriers for compounds 7 and 9 were characterized with the semiempirical AM1 method. ${ }^{15}$ The barriers for chloromethyl and dichloromethyl group rotations were computed in steps of $10^{\circ}$, and the potential energy curves were visualized with the MATLAB program package. The gaugeincluding atomic orbital (GIAO) ${ }^{17}$ method was employed at the DFT B3LYP/6-311G* level to calculate ${ }^{13} \mathrm{C}$ isotropic shielding constants $(\sigma)$ for TMS $(183.6 \mathrm{ppm})$ and the chlorinated dihydrocamphenes studied. All calculations were done using the Gaussian98 program ${ }^{39}$ running on IBM RISC/6000 320 and Silicon Graphics Origin200 workstations.

\section{Acknowledgements}

This work was financially supported by the European Commission (Contract n:o ENV4-CT970468) and INTAS (Project n:o 96-1990). We are grateful to Mr R. Kauppinen for his help in running the NMR spectra.

\section{References}

1. Saleh, M. A. Rev. Environ. Cont. Toxicol. 1991, 118, 1.

2. Jennings, B. H.; Herscbach, G. B. J. Org. Chem. 1965, 30, 3902.

3. Hainzl, D.; Burhenne, J.; Parlar, H. Chemosphere 1993, 27, 1857.

4. Walter, B.; Ballschmiter, K. Fresenius J. Anal. Chem. 1991, 340, 245.

5. Krock, B.; Vetter, W.; Luckas, B.; Scherer, G. Chemosphere 1999, 39, 133.

6. Seiber, J. N.; Landrum, P. F.; Madden, S. C.; Nugent, K. D.; Winterlin, W. L. J. Chromatogr. 1975, 114, 361.

7. Landrum, P. F.; Pollock, G. A.; Seiber, J. N.; Hope, H.; Swanson, K. L. Chemosphere 1976, $5,63$.

8. Hainzl, D.; Burhenne, J.; Barlas, H.; Parlar, H. Fresenius J. Anal. Chem. 1995, 351, 271.

9. Tribulovich, V. G.; Nikiforov, V. A.; Bolshakov, S. Organohalogen Compounds 1996, 28, 385.

10. Bidleman T. F.; Walla, M. D.; Muir, D. C. G.; Stern, G. A. Environ. Toxicol. Chem. 1993, 12, 701.

11. Parlar, H. Nachr. Chem. Tech. Lab. 1991, 39, 26. 
12. Vetter, W.; Scherer, G. Chemosphere 1998, 37, 2525.

13. Casida, J. E.; Holmstead, R. L.; Khalifa, S.; Knox, J. R.; Ohsawa, T.; Palmer, K. J.; Wong, R. Y. Science 1974, 183, 520.

14. Naumann, K, J. Prakt. Chem. 1999, 341, 417.

15. Dewar, M. J. S.; Zoebisch, E.; Healy, E. F.; Stewart, J. J. P. J. Am. Chem. Soc. 1985, 107, 3902.

16. Bühl, M.; Gauss, J.; Hofmann, M.; von Ragué Schleyer, P. J. Am. Chem. Soc. 1993, 115, 12385.

17. Wolinski, K.; Hinton, J. F.; Pulay, P. J. Am. Chem. Soc. 1990, 112, 8251.

18. Weast, R. C. CRC Handbook of Chemistry and Physics; $70^{\text {th }}$ Ed CRC Press: Boca Raton, 1989, p F-188.

19. Palmer, K. J.; Wong, R. Y.; Lundin, R. E.; Khalifa, S.; Casida, J. E. J. Am. Chem. Soc. 1975, 97, 408

20. Frenzen, G.; Hainzl, D.; Burhenne, J.; Parlar, H. Chemosphere 1994, 28, 2067.

21. Koivisto J.; Kolehmainen, E.; Nikiforov, V.; Nissinen, M.; Linnanto, J.; Lahtiperä, M.; Miltsov, S. A.; Karavan, V. S. Chemosphere, accepted.

22. Derome, A. E.; Williamson, M. P. J. Magn. Reson. 1990, 88, 177.

23. Bax, A.; Davis, D. G. J. Magn. Reson. 1985, 63, 207.

24. Laatikainen, R.; Niemitz, M.; Weber, U.; Sundelin, J.-P.; Hassinen, T.; Vepsäläinen, J. J. Magn. Reson., A 1996, 120, 1.

25. PERCH Software, Version 1/99, distributed by PERCH Project, Department of Chemistry, University of Kuopio, Kuopio, Finland, 1999.

26. Günther, H. NMR spectroscopy. Basic principles, concepts, and applications in chemistry; $2^{\text {nd }}$ Edn; John Wiley \& Sons: Chichester, 1995, p 124.

27. Bax, A.; Griffey, R. H.; Hawkins, B. L. J. Magn. Reson. 1983, 55, 301.

28. Bax, A.; Subramanian, S. J. Magn. Reson. 1986, 67, 565.

29. Hurd, R. E.; John, B. K. J. Magn. Reson. 1991, 91, 648.

30. Bax, A.; Summers, M. F. J. Am. Chem. Soc. 1986, 108, 2093.

31. Nikiforov, V.; Karavan, V.; Miltsov, S. Chemosphere 2000, 41, 467.

32. Nikiforov, V.; Tribulovich, V.; Bolshakov, S. Organohalogen Compounds 1996, $28,355$.

33. Tribulovich, V.; Nikiforov, V.; Karavan, V.; Miltsov, S.; Bolshakov, S. Organohalogen Compounds 1994, 19, 97.

34. Malayiandi, M.; Buchanan, G. W.; Nikiforov, V.; Williams, D. T. Chemosphere 1993, 27, 1849.

35. Nikiforov, V.; Karavan, V.; Miltsov, S. Organohalogen Compounds 1999, 41, 605.

36. Otwinowski, Z.; Minor, W. In Methods in Enzymology; Vol. 276: Macromolecular Crystallography, part A, Carter, C. W. Jr.; Sweet, R. M., Eds; Academic Press: 1997; p 307.

37. Sheldrick, G. M. Acta Cryst. 1990, A46, 467.

38. Sheldrick, G. M. SHELXL-97 - A program for crystal structure refinement, University of Göttingen: Germany, 1997.

39. Frisch, M. J.; Trucks, G. W.; Schlegel, H. B.; Scuseria, G. E.; Robb, M. A.; Cheeseman, J. 
R.; Zakrzewski, V. G.; Montgomery, J. A. Jr; Stratmann, R. E.; Burant, J. C.; Dapprich, S.; Millam, J. M.; Daniels, A. D.; Kudin, K. N.; Strain, M. C.; Farkas, O.; Tomasi, J.; Barone, V.; Cossi, M.; Cammi, R.; Mennucci, B.; Pomelli, C.; Adamo, C.; Clifford, S.; Ochterski, J.; Petersson, G. A.; Ayala, P. Y.; Cui, Q.; Morokuma, K.; Malick, D. K.; Rabuck, A. D.; Raghavachari, K.; Foresman, J. B.; Cioslowski, J.; Ortiz, J. V.; Stefanov, B. B.; Liu, G.; Liashenko, A.; Piskorz, P.; Komaromi, I.; Gomperts, R.; Martin, R. L.; Fox, D. J.; Keith, T.; Al-Laham, M. A.; Peng, C. Y.; Nanayakkara, A.; Gonzalez, C.; Challacombe, M.; Gill, P. M. W.; Johnson, B.; Chen, W.; Wong, M. W.; Andres, J. L.; Gonzales, C.; Head-Gordon, M.; Replogle, E. S.; Pople, J. A. GAUSSIAN 98, Revision A.6. Gaussian, Inc., Pittsburgh PA, 1998. 